\title{
Selective preoperative endoscopic retrograde cholangiography with sphincterotomy avoids bile duct exploration during laparoscopic cholecystectomy
}

\begin{abstract}
A policy of preoperative endoscopic retrograde cholangiography (ERC) for suspected bile duct stones was used in 1507 patients considered for laparoscopic cholecystectomy in three district general hospitals. Altogether 306 patients underwent ERC, and bile duct cannulation was achieved in $276(90 \%)$. Bile ducts were cleared by endoscopic sphincterotomy in 128 of 161 patients $(79 \%)$ with proven duct stones. Laparoscopic cholecystectomy was completed in 1396 patients. Ten laparotomies were necessary for complications of laparoscopic cholecystectomy. The complication rate for endoscopic sphincterotomy/laparoscopic cholecystectomy was $2 \cdot 7 \%$, with no mortality. Overall, a combined endoscopic/laparoscopic approach succeeded in 1386 patients $(92 \%)$. Fourteen patients $(1 \%)$ had retained stones during a median of 14 months (range 1-42) follow up, all of which were removed by ERC/endoscopic sphincterotomy. If a policy of selective ERC before laparoscopic cholecystectomy is used for all patients with symptomatic gall stones, most will avoid an open operation and laparoscopic exploration of the bile duct is not necessary.

(Gut 1995; 37: 576-579)
\end{abstract}

Keywords: gall stone, endoscopic retrograde cholangiography, laparoscopic cholecystectomy.

Department of Surgery, Musgrove Park Hospital, Taunton

C R B Welbourn D Mehta

I A Eyre-Brook

Department of Surgery, Frenchay Hospital, Bristol C P Armstrong

Department of Surgery, Gloucestershire Royal Hospital, Gloucester $M$ W L Gear

Correspondence to: Mr I A Eyre-Brook, Department of Surgery, Musgrove Park Hospital, Taunton TA1 5DA

Accepted for publication 31 January 1995
Laparoscopic cholecystectomy has rapidly become the standard technique for elective removal of symptomatic stones in the gall bladder. $^{1}$ At least $7 \%$ of patients who undergo cholecystectomy also have stones in the bile duct. ${ }^{23}$ Although small bile duct stones may pass spontaneously, they are usually removed electively since there is evidence that most will lead to symptoms in time. ${ }^{2}$

Unlike gall bladder stones, considerable controversy exists about the most appropriate method for removing bile duct stones. $^{3}$ Laparoscopic bile duct exploration during laparoscopic cholecystectomy has been advocated but is not used widely, ${ }^{4}$ and by adding operating time has logistic implications for planning operating theatre use. An alternative method is to remove bile duct stones preoperatively by endoscopic retrograde cholangiography (ERC) and endoscopic sphincterotomy. ${ }^{5}$
Since ERC is routinely available in our hospitals, we used a policy of performing ERC/endoscopic sphincterotomy before laparoscopic cholecystectomy on all patients suspected of having bile duct stones, and report our experience.

\section{Methods}

We studied all patients considered for laparoscopic cholecystectomy for symptomatic gall bladder stones from October 1990 in the Frenchay and Taunton hospitals, and June 1991 in Gloucester, until April 1994. Patients of one surgeon in Frenchay and all surgeons performing laparoscopic cholecystectomy in Taunton and Gloucester were included. All patients had ultrasound scanning of the gall bladder and bile ducts and liver function tests were measured. Patients were suspected of having bile duct stones according to established criteria ${ }^{6}$ if one or more of the following indications was present: jaundice or cholangitis; pancreatitis; a definite history of jaundice, including pale stools and dark urine; bile duct diameter $>7 \mathrm{~mm}$ or a visible stone in the bile duct on ultrasound scanning; raised liver function test values (serum bilirubin and alkaline phosphatase).

Our policy was as follows:

- To undertake ERC for all patients with suspected bile duct stones.

- To remove any bile duct stones by endoscopic sphincterotomy.

- To perform laparoscopic cholecystectomy on all patients with no indication for ERC, all patients with normal ERC (that is, no bile duct stones found), and all patients with bile duct stones cleared by ERC/endoscopic sphincterotomy.

- To perform open cholecystectomy, with or without exploration of the bile duct, on all patients with bile ducts that had not been cleared by endoscopic sphincterotomy and all patients in whom bile duct cannulation failed on ERC.

Patients with jaundice, cholangitis, or pancreatitis had ERC during their initial admission to hospital. Patients whose only indications were a history of jaundice, ultrasound findings, or raised liver function test values had ERC on a convenient endoscopy list before laparoscopic cholecystectomy. Patients were given Buscopan to facilitate bile duct cannulation and all stones were extracted by endoscopic sphincterotomy. Pre-cut 
TABLE I Outcome of preoperative endoscopy

\begin{tabular}{|c|c|c|c|c|c|c|c|}
\hline & \multicolumn{5}{|c|}{ Indication for $E R C^{\star}$} & \multirow[b]{2}{*}{$\begin{array}{l}\text { Total } \\
\text { patients (\%) }\end{array}$} & \multirow[b]{2}{*}{$\begin{array}{l}\text { Procedures } \\
\text { required }\end{array}$} \\
\hline & $\begin{array}{l}\text { Faundicel } \\
\text { cholangitis }\end{array}$ & Pancreatitis & $\begin{array}{l}\text { History of } \\
\text { jaundice }\end{array}$ & $\begin{array}{l}\text { Ultrasound } \\
\text { findings }\end{array}$ & $\begin{array}{l}\text { Raised } \\
\text { LFT }\end{array}$ & & \\
\hline $\begin{array}{l}\text { Normal ERC } \\
\text { Duct stones cleared by ES } \\
\text { Duct stones not cleared by ES } \\
\text { Failed cannulation }\end{array}$ & $\begin{array}{r}22 \\
51 \\
15 \\
6\end{array}$ & $\begin{array}{r}30 \\
35 \\
4 \\
9\end{array}$ & $\begin{array}{r}22 \\
14 \\
4 \\
5\end{array}$ & $\begin{array}{r}24 \\
12 \\
10 \\
4\end{array}$ & $\begin{array}{r}17 \\
16 \\
0 \\
6\end{array}$ & $\begin{array}{r}115(37) \\
128(42) \\
33(11) \\
30(10)\end{array}$ & $\begin{array}{r}119 \\
283 \\
54 \\
36\end{array}$ \\
\hline Total & 94 & 78 & 45 & 50 & 39 & $306(100)$ & 492 \\
\hline
\end{tabular}

*One indication per patient was recorded using a heirarchy from jaundice/cholangitis through to elevated LFTs. Thus a patient with jaundice or cholangitis may also have had another indication(s) but a patient recorded as having raised liver function tests (LFT) had no other indication. ERC=endoscopic retrograde cholangiography; ES = endoscopic spincterectomy.

sphincterotomy was not routinely performed. Prolonged attempts to remove numerous or large stones at ERC were avoided and in this situation an open duct exploration was considered better.

Laparoscopic cholecystectomy or open cholecystectomy and operative cholangiography with or without exploration of the bile duct were performed according to the protocol. In one hospital (Frenchay), patients in whom bile duct cannulation failed underwent intravenous cholangiography (IVC) followed by laparoscopic cholecystectomy, or open cholecystectomy if stones were present. Laparoscopic cholecystectomy was performed using standard technique. ${ }^{7}$ Intraoperative cholangiography was not routinely performed. All patients with clinical evidence of retained stones after laparoscopic cholecystectomy underwent ERC/endoscopic sphincterotomy, as did patients with postoperative bile leaks. ${ }^{8}$ The outcome of ERC, complications of ERC/endoscopic sphincterotomy and laparoscopic cholecystectomy, the conversion rate of laparoscopic cholecystectomy, and results of ERC/endoscopic sphincterotomy for retained stones were recorded. Conversion was defined as open cholecystectomy not involving another procedure performed during an operation that had started laparoscopically.

\section{Results}

Altogether $306(20 \%)$ of 1507 consecutive patients (median age 50, range 16-93) considered for laparoscopic cholecystectomy underwent preoperative ERC. The indications for and the outcome of preoperative ERC are shown (Table I). The predictive values for each indication in detecting bile duct stones were: jaundice/cholangitis $75 \%$, pancreatitis $56 \%$, history of jaundice $45 \%$, ultrasound findings $48 \%$, raised liver function tests $48 \%$. All 115 patients with a normal ERC and all 128 patients whose duct stones were cleared by endoscopic sphincterotomy underwent laparoscopic cholecystectomy.

The 33 patients in whom the bile duct could not be cleared by endoscopic sphincterotomy

TABLE II Complications of endoscopic sphincterectomy in 161 patients

\begin{tabular}{lll}
\hline Complication & Patients & Outcome \\
\hline Pancreatitis & 2 & Settled \\
Abdominal pain (amylase normal) & 3 & Settled \\
Total & $5(3 \cdot 1 \%)$ & \\
\hline
\end{tabular}

underwent open operation. Seven of these patients had choledocho-duodenostomy and in one the bile duct was normal on cholangiogram and exploration was not carried out. Two patients had Mirizzi's syndrome. There were five complications of endoscopic sphincterotomy (Table II) and no complication from ERC alone.

Twenty of the 30 patients in whom bile duct cannulation was not achieved underwent open exploration. Failure of cannulation was due to Polya gastrectomy in three patients. IVC was undertaken in eight patients, all of whom were seen to have normal bile ducts and underwent laparoscopic cholecystectomy. In two patients in whom bile duct cannulation failed the protocol was not followed. These underwent laparoscopic cholecystectomy without IVC and one had a retained stone.

Laparoscopic cholecystectomy was started in 1454 patients and converted to an open operation in $58(4 \%)$. There were two bile duct injuries $(0 \cdot 14 \%)$, one of which was repaired primarily, and the second when the patient developed signs of a major bile leak (Table III). Both patients were symptom free at the end of the study. There were 10 bile leaks treated by laparotomy, ERC, or percutaneous drain. Allowing for conversions and 10 complications requiring laparotomy 1386 of 1507 patients considered for laparoscopic cholecystectomy avoided an open operation $(92 \%)$. The overall complication rate for ERC/endoscopic sphincterotomy/laparoscopic cholecystectomy was $2 \cdot 7 \%$.

Patients were followed up for a median 14 months (range 1-42). During follow up 14 patients had a retained stone removed by ERC and four others had clinical evidence of a retained stone but a subsequent ERC was normal, suggesting that the stone had been passed (Table IV).

\section{Discussion}

We report a prospective evaluation of the results of selective ERC before laparoscopic cholecystectomy in a large consecutive series of patients considered for laparoscopic cholecystectomy in three district general hospitals. Most patients (92\%) had either a laparoscopic procedure only or a combined endoscopic/ laparoscopic procedure to remove their gall stones, with no mortality. This figure includes all patients who underwent laparoscopic cholecystectomy during the 'learning curve' period in each hospital and all complications 
TABLE III Complications of laparoscopic cholecystectomy (LC) in 1454 patients

\begin{tabular}{|c|c|c|}
\hline Complication & Patients & Outcome \\
\hline \multicolumn{3}{|l|}{ Biliary $(1 \cdot 0 \%)$ : } \\
\hline Bile duct injury & 2 & Hepatico-jejunostomy, repair of bile duct hole \\
\hline Bile leak & 10 & $\begin{array}{l}5 \text { Settled through laparotomies, } 3 \text { settled } \\
\text { through ERC, } 2 \text { settled through drain only }\end{array}$ \\
\hline Haemorrhage & 2 & Laparotomy \\
\hline Subphrenic abscess & 1 & Settled through drain \\
\hline \multicolumn{3}{|l|}{ Non-biliary $(1 \cdot 3 \%)$ : } \\
\hline Small bowel injury (port insertion) & 1 & Repaired before laparascopic cholecystectomy \\
\hline \multirow{2}{*}{\multicolumn{3}{|c|}{ Small bowel obstruction (Meckel's }} \\
\hline & 1 & Laparotomy \\
\hline Atelectasis (surgical emphysema) & 1 & Settled \\
\hline Port site hernia & 1 & Repaired \\
\hline Haemoglobin fall & 1 & Transfused \\
\hline Port site haematoma & 1 & Settled \\
\hline Others including acute retention & 14 & Settled \\
\hline Total & $35(2 \cdot 4 \%)$ & \\
\hline
\end{tabular}

of ERC/endoscopic sphincterotomy and laparoscopic cholecystectomy that required an open operation. The overall complication rate of $2.7 \%$ and the bile duct injury rate of $0 \cdot 14 \%$ compare favourably with published reports of laparoscopic cholecystectomy and open cholecystectomy. ${ }^{9-11}$ The results show that a combined endoscopic/laparoscopic approach to removing gall stones is successful in most patients and can be undertaken safely in routine practice in district general hospitals.

It is unclear from available data whether a policy of selective ERC and laparoscopic cholecystectomy is applicable to all patients undergoing cholecystectomy. In this series $20 \%$ of patients had preoperative ERC. The overall incidence of bile duct stones was $11 \%$, which is in keeping with previously reported data for open cholecystectomy. ${ }^{23}$ In seven recently published series using the same preoperative indications, preoperative ERC was performed in only $4-14 \%$ of patients and the incidence of bile duct stones was $3.9 \%$ (166 in 4289 patients). ${ }^{12-18}$ This low incidence suggests selection bias, in that some patients with bile duct stones may have been excluded from consideration for laparoscopic cholecystectomy in these series. No patient was excluded from our study because of the presence or size of bile duct stones, and our results suggest that this protocol can be applied to all patients with symptomatic gall stones who are undergoing cholecystectomy. Preliminary results from one centre have shown similar findings. ${ }^{19}$

Eighteen patients had clinical evidence of a retained bile duct tone after laparoscopic cholecystectomy $(1 \cdot 2 \%)$, similar to the rate found in other series. ${ }^{12} 13$ All retained stones were successfully removed by ERC/endoscopic

TABLE IV Retained stones after laparoscopic cholecystectomy

\begin{tabular}{lcll}
\hline Preoperative indication & Patients & $\begin{array}{l}\text { Preoperative } \\
\text { ERC }\end{array}$ & $\begin{array}{l}\text { Duct cleared at } \\
\text { postoperative ERC/ES }\end{array}$ \\
\hline None & 6 & No & Yes \\
History of jaundice & 1 & Normal & Yes \\
Ultrasound findings & 1 & Normal & Yes \\
Liver function tests & 1 & Normal & Yes \\
History of jaundice & 1 & Failed & Yes \\
Ultrasound findings (missed) & 1 & No & Yes \\
Liver function tests (missed) & 3 & No & Normal \\
None & 3 & No & Normal \\
Liver function tests (missed) & 1 & \\
Total & $18 ; 14$ definite (1\%), 4 likely & \\
\hline
\end{tabular}

$\mathrm{ERC}=$ endoscopic retrograde cholangiography; $\mathrm{ES}=$ endoscopic sphincterectomy. sphincterotomy. Strict adherence to the protocol should have identified five of the 14 patients with definite retained stones. The protocol itself missed the remaining nine stones. Therefore, this protocol identifies $95 \%$ of patients (166 of 175) with proven bile duct stones.

A policy of selective ERC before laparoscopic cholecystectomy has not been welcomed widely for several reasons. ${ }^{20}{ }^{21}$ Firstly, the extra workload due to the increased requirement for ERCs in this policy may lead to added complications. ${ }^{2022}$ Our results, with a complication rate from endoscopic sphincterotomy of $3.7 \%$, do not support this. Secondly, many ERC are normal and therefore unnecessary. In this series 209 ERC performed in 178 patients were either normal or did not prevent these patients from having an open operation. The overall morbidity for endoscopic sphincterotomy/laparoscopic cholecystectomy is proportionately less, however, than that for open duct exploration in both the young and the elderly. ${ }^{23}$ The results of laparoscopic duct exploration in non-specialist centres are unknown. The few series reporting laparoscopic duct exploration on selected patients from specialist centres suggest a higher complication rate than that achieved in this series using ERC/laparoscopic cholecystectomy. ${ }^{2124}$ Thirdly, there is a perceived risk of more complications from endoscopic sphincterotomy in those with normal sized bile ducts. $^{25}$ In contrast, others have not found this. ${ }^{26}$ Finally, there is concern about the long term morbidity of endoscopic sphincterotomy, for instance late stenosis. ${ }^{22} 27$ However, the observation that this technique improves the morbidity of patients with cholangitis ${ }^{28}$ or pancreatitis $^{29}$ lends further support to ERC/endoscopic sphincterotomy. Thus, the observed benefits of the policy of selective ERC/laparoscopic cholecystectomy at present strongly support its continued use.

The large number of preoperative ERCs in this series might be reduced by the adoption of stricter criteria for ERC but at the risk of more retained stones after laparoscopic cholecystectomy. Some authors avoid preoperative ERC and reserve this procedure for the management of symptomatic duct stones after laparoscopic cholecystectomy. ${ }^{51213}$ At present no data are available on the risks of leaving stones in the duct during laparoscopic cholecystectomy. Although some of these stones may pass spontaneously, the postoperative risks of bile leakage, pancreatitis, and cholangitis may well be increased by duct stones. Another disadvantage of postoperative ERC is that some patients would eventually need open duct exploration in addition to laparoscopic cholecystectomy if duct stones could not be removed by endoscopic sphincterotomy.

Series that present the results for laparoscopic cholecystectomy alone or combined with ERC emphasise the benefits of laparoscopic techniques. Our data confirm low morbidity and show that only a proportion of patients continue to need an open operation $8 \%$ in this series. We suggest that selective ERC before laparoscopic cholecystectomy is a 
workable policy that can be used for all patients with symptomatic gall stones.

1 National Institutes of Health Consensus Development Conference Statement on Gallstones and Laparoscopic

2 Johnson AG, Hosking SW. Appraisal of the management of bile duct stones. Br f Surg 1987; 74: 555-60

3 Perissat J, Huibregtse K, Keane FBV, Russell RCG, Neoptolomos JP. Management of bile duct stones in the era of laparoscopic cholecystectomy. Br F Surg 1994; 81: 799-810.

4 Talamini MA. Controversies in laparoscopic cholecystectomy: contraindications, cholangiography, pregnancy and avoidance of complications. Baillière's Clin Gastroenterol 1993; 7 (4): 881-96.

5 Cotton PB. Endoscopic Retrograde Cholangiopancreatography and laparoscopic cholecystectomy. Am $\mathcal{F}$ Surg 1993; 165: 474-8.

6 Hauer-Jensen M, Kåresen R, Nygaard K, Solheim K, Amlie $\mathrm{E}$, Havig $\emptyset$, et al. Predictive Ability of Choledocholithiasis Indicators. A Prospective evaluation. Ann Surg 1985; 202 64-8.

7 Russell RCG. Minimally invasive surgery. General surgery: biliary surgery. $B M \mathcal{F} 1993 ; 307$ : 1266-9.

8 Mortensen J, Kruse A. Endoscopic management of postoperative bile leaks. Br f Surg 1992; 79: 1339-41.

9 Macintyre IMC, Wilson RG. Laparoscopic cholecystectomy. Br f Surg 1993; 80: 552-9.

10 Gouma DJ, Go PMNYH. Bile duct injury during laparoscopic and conventional cholecystectomy. $\mathcal{f} \mathrm{Am}$ Coll Surg 1994; 178: 229-33.

11 Southern Surgeons Club. A prospective analysis of 1518 laparoscopic cholecystectomies. N Engl f Med 1991; 324: laparosc $1073-8$.

12 Barkun JS, Fried GM, Barkun AN, Sigman HH, Hinchey EJ, Garzon J, et al. Cholecystectomy without operative cholangiography. Implications for common bile duct injury and retained common bile duct stones. Ann Surg 1993; 218: 371-9.

13 Leitman IM, Fisher ML, McKinley MJ, Rothman R, Ward RJ, Reiner DS, et al. The evaluation and management of known or suspected stones of the common bile duct in the era of minimal access surgery. Surg Gynecol Obstet 1993; 176: 527-33.

14 Mol L-R, Yau M-P, Hwang M-H, Lin R-C, Kuo J-Y, Tsai in laparoscopic cholecystectomy. Fournal of Laparoin laparoscopic cholecystectomy.

15 Franceschi D, Brandt C, Margolin D, Szopa B, Ponsky J Priebe $\mathrm{P}$, et al. The management of common bile duct stones in patients undergoing laparoscopic cholecystectomy. Am Surg 1993; 59: 525-32.

16 Frazee RC, Roberts J, Symmonds R, Hendricks JC, Snyder $\mathrm{S}$, Smith R, et al. Combined laparoscopic and endoscopic management of cholelithiasis and choledocholithiasis. Am I Surg 1993; 166: 702-6.

17 Hawasli A, Lloyd L, Pozios V, Veneri R. The role of endoscopic retrograde cholangio-pancreaticogram in laparoscopic cholecystectomy. Am Surg 1993; 59.285

18 O'Rourke NA, Askew AR, Cowen AE, Roberts R, Fielding GA. The role of ERCP and endoscopic sphincterotomy in the era of laparoscopic cholecystectomy. Aust NZ F Surg 1993; 63: 3-7.

19 Widdison AL, Longstaff AJ, Armstrong CP. Combined laparoscopic and endoscopic treatment of gallstones and bile duct stones: a prospective study. Br $\mathcal{F}$ Surg $1994 ; 81$ : 595-7.

20 Swanstrom LL. Laparoscopic approaches to the common bile duct stone: transcystic duct exploration, choledochostomy and stone fragmentation. Baillière's Clin Gastroenterol 19my and stone fragm 7 (4): 887-919.

21 Phillips EH, Carroll BJ, Pearlsetein AR, Daykhovsky L, Fallas MJ. Laparoscopic choledochoscopy and extraction of common bile duct stones. World f Surg 1993; 17: 22-8.

22 Fletcher DR. Changes in the practice of biliary surgery and ERCP during the introduction of laparoscopic cholecystectomy to Australia: their possible significance. Aust NZ Surg 1994; 64: 75-80.

23 Irvin TT, Arnstein PM. Management of symptomatic gallstones in the elderly. Br $\mathcal{F}$ Surg 1988; 75: 1163-5.

24 Berci G, Morgenstern L. Laparoscopic management of common bile duct stones. A multi-institutional SAGES study. Surg Endosc 1994; 8: 1168-75.

25 Sherman S, Ruffolo TA, Hawes RH, Lehman GA. Complications of endoscopic sphincterotomy. A prospective series with emphasis on the increased risk associated with sphincter of Oddi dysfunction and nondilated bile ducts. Gastroenterology 1991; 101: 1068-75.

26 Wilson MS, Tweedle DEF, Martin DF. Common bile duct diameter and complications of endoscopic sphincterotomy. Br f Surg 1992; 79: 1346-7.

27 McEntee G, Grace PA, Bouchier-Hayes D. Laparoscopic cholecystectomy and the common bile duct. $\mathrm{Br} \mathcal{F}$ Surg 1991; 78: 385-6.

28 Neoptolemos JF, Carr-Locke DL, Leese T, James D. Acute cholangitis in association with acute pancreatitis: incidence, clinical features and outcome in relation to ERCP dence, clinical features and outcome in relation to ERCP and endos.

29 Fan S-T, Lai ECS, Mok FPT, Lo C-M, Zheng S-S, Wong J. Early treatment of acute biliary pancreatitis by endoscopic papillotomy. $N$ Engl $\mathcal{F}$ Med 1993; 328: 228-32. 